\title{
Traslación de textos medievales en lengua vernácula. Reflexiones a partir de una experiencia de traducción colaborativa de la Vie seinte Osith, virge e martire
}

\begin{abstract}
María Eugenia Alcatena maevalcatena@gmail.com Instituto de Investigaciones Bibliográficas y Crítica Textual - Consejo Nacional de Investigaciones Científicas y Técnicas / Universidad de Buenos Aires,

Argentina
\end{abstract}

María Dumas

mariadumas@filo.uba.ar

Facultad de Filosofía y Letras, Universidad de Buenos Aires, Argentina

\begin{abstract}
Resumen
En el presente artículo analizamos la elaboración e implementación de un método colaborativo de trabajo orientado a la resolución de las dificultades que nos planteó la traducción de la Vie seinte Osith, un relato hagiográfico escrito en francés antiguo hacia finales del siglo XII. En primer lugar, examinamos algunas peculiaridades distintivas de la textualidad medieval que presentan problemas específicos para la traducción. Procedemos, luego, a evaluar los beneficios, así como los desafíos, que implicó la cooperación: establecer una dinámica, pautar actividades, definir criterios. Como resultado de este proceso, arribamos a un método de trabajo que ofrecemos a consideración como caso testigo de labor colaborativa.
\end{abstract}

Palabras clave: traducción colaborativa, textualidad medieval, alteridad, traducción intertemporal, hagiografía.

1 Este trabajo se enmarca en el proyecto FILO:CYT "La vida de Santa Osith, virgen y mártir: traducción, edición y estudio de una leyenda hagiográfica de la Inglaterra bajomedieval (siglos XII-XIV). Hacia una reconsideración de la relevancia de la hagiografía en la emergencia de las literaturas en lengua vernácula", dirigido por ambas autoras y radicado en el Instituto de Filología y Literaturas Hispánicas "Dr. Amado Alonso" de la Facultad de Filosofía y Letras de la Universidad de Buenos Aires para el período 2019-2021. 


\section{Translation of Medieval Vernacular Texts. Reflections Based on a Collaborative Translation of the Vie seinte Osith, virge e martire}

\section{Abstract}

This paper examines the design and implementation of a collaborative translation method aimed at addressing the difficulties encountered in the process of translating the Vie seinte Osith — an Old French hagiographical poem written in the late $12^{\text {th }}$ century. We will first describe a number of features peculiar to medieval texts, pointing out the specific problems they pose to contemporary translators. Then, we will assess the advantages, as well as the challenges, raised in collaborative translation: establishing a collaborative dynamics, planning activities, outlining criteria. As a result of this process, we have developed a work method, which we are submitting here to consideration as a case study of collaborative translation.

Keywords: collaborative translation, medieval textuality, alterity, intertemporal translation, hagiography.

\section{Translation de textes médiévaux en langue vernaculaire. Réflexions à partir d'une expérience de traduction collaborative de la Vie seinte Osith, virge e martire}

\section{Résumé}

Nous nous proposons, dans cet article, d'analyser l'élaboration et la mise en œuvre d'une méthode de travail collaborative, orientée vers la résolution des difficultés posées par la traduction de la Vie seinte Osith, un récit hagiographique écrit en ancien français à la fin du xile siècle. Tout d'abord, nous examinons quelques traits distinctifs de la textualité médiévale qui ont soulevé des problèmes au moment de la traduction. Ensuite, nous procédons à l'évaluation des avantages et des des défis posés par le travail collaboratif : établir une dynamique de travail, planifier des activités, définir des critères. À la suite de ce processus, nous parvenons à formuler une méthode de travail, que nous présentons comme un cas témoin de traduction collaborative.

Mots-clès : traduction collaborative, textualité médiévale, altérité, traduction intertemporelle, hagiographie. 


\section{Introducción}

La Vie seinte Osith, virge e martire es un poema hagiográfico compuesto en Inglaterra, en el dialecto anglonormando del francés antiguo, hacia fines del siglo XII. Como la inmensa mayoría de los relatos medievales sobre vidas de santos (un corpus vasto y diverso, de una pregnancia inmensa en el imaginario y la literatura, tanto religiosa como secular, de la Baja Edad Media), esta narración no había sido, hasta ahora, traducida al castellano. Previamente existía una traducción al inglés, realizada por Jane Dick Zatta y revisada por Jocelyn Wogan-Browne (2005), además de dos ediciones críticas del texto original: la de Alfred Thomas Baker (1911) y la de Delbert W. Russell (2005).

A partir de nuestra experiencia concreta con la traducción del relato, el presente artículo se propone, en primera instancia, identificar y reflexionar sobre una serie de peculiaridades intrínsecas a la traducción de textos medievales en lenguas vernáculas. A continuación, pondremos a consideración el modo en que procuramos, a través de la labor colaborativa, resolver esas dificultades propias de la textualidad medieval y su traslación, lingüística y cultural, a nuestro contexto inmediato argentino e hispanoamericano. Explicitaremos, pues, cuáles fueron la metodología y los criterios adoptados en el proceso. En su desarrollo fuimos delineando y logramos arribar a una dinámica de trabajo en equipo eficaz y adaptada a los desafíos planteados por el texto. Describiremos esta dinámica, en sus vacilaciones y sus progresivos hallazgos, con la perspectiva de que pueda servir de referencia para experiencias futuras, propias y ajenas.

\section{Traducir la alteridad medieval}

La textualidad medieval y, en particular, la emergente producción escrita en lenguas ver- náculas que comienza a consolidarse en el continente europeo a fines del siglo $\mathrm{XI}^{2}$ presentan ciertas características distintivas que añaden desafíos específicos a la labor de la traducción.

Una de las primeras consideraciones a tener en cuenta es que se trata de textos producidos en el marco de una cultura manuscrita, signados por la variabilidad (lo que Paul Zumthor identificó como la mouvance esencial del texto medieval - 1972, p. 71- y Bernard Cerquiglini reformuló bajo el concepto de variance -1989-). Ninguna copia es exactamente igual a otra; las equivocaciones involuntarias y las modificaciones a conciencia hacen que los textos vivan en variantes, en constante transformación. Los textos se reformulan y mutan atendiendo a los contextos concretos en que circularán, al gusto y las modas cambiantes, a los intereses en juego, a la intencionalidad de quien decide copiarlos. No contamos entonces, por lo general, con un único "original" autorizado, un hipotexto certero y definitivo al cual remitirnos. Cada manuscrito, por otra parte, transmite inevitablemente un texto en mayor o menor medida corrupto, con errores de copia de distintos tipos. La realidad material de la transmisión de cada texto determinará, por lo tanto, una serie particular de problemas que deben considerarse. Cuando un texto ha sido conservado a través de diversos testimonios y variantes, por caso, es imperioso cotejarlos de manera tal de reconstruir el mejor texto posible (teniendo en cuenta, por otra parte, que los criterios de edición posibles son varios y divergentes, y que esa reconstrucción hipotética dependerá de los parámetros

2 En las áreas románicas, las primeras manifestaciones de una escritura protorromance (puesto que en ellas la lengua vernácula se manifiesta aún muy próxima al latín) despuntan tímidamente a mediados del siglo Ix. Se trata, sin embargo, de testimonios aislados. 
que adopte cada investigador). Cuando, por el contrario, un texto ha sido transmitido por un único testimonio, resulta imposible acudir a otros escritos alternativos para intentar resolver omisiones, lagunas, errores de copia evidentes, lecturas difíciles o pasajes de sentido oscuro o directamente desconcertante. Como puede imaginarse, se trata de variables que acarrean implicancias concretas en la labor de los editores y los traductores modernos. ${ }^{3}$

Este último es el caso del texto que nos propusimos traducir, conservado en un único códice (el llamado manuscrito Campsey, BL Additional 70513). Esto entrañó, por ejemplo, que al encontrar construcciones de sintaxis equívoca, frases de significado oscuro, ambiguas o contrarias al que parecería ser el sentido general del relato, o bien palabras discordantes, empleadas en un contexto de uso o con un matiz semántico anómalo para los textos del período, no pudiéramos consultar otras variantes (lo que nos hubiera permitido, tal vez, dilucidar el sentido de algunos de esos pasajes acudiendo a opciones de lectura más clara, o identificar errores del copista) y tuviéramos que recurrir a nuestro mejor juicio para resolver la traducción.

El siguiente pareado, por ejemplo, ofrece un caso de relativa indeterminación:

3 Por supuesto, las tareas del editor y el traductor son muy diferentes. Sin embargo, incluso cuando se toma como base para la traducción una edición crítica preexistente (como fue nuestro caso), a menudo "el traductor se convierte también en editor", en palabras de Joaquín Rubio Tovar (1999, p. 51). Esto se verifica claramente cuando, por ejemplo, el traductor toma decisiones sobre aspectos fundamentales del texto, como pueden ser la puntuación o el ordenamiento de versos, diferentes a las favorecidas por la edición crítica de la que se parte. En algunos de los pasajes que analizaremos en el desarrollo de este artículo se trasluce esta cuestión.
Del cerf li membre ke il tant suivi,

Quide ke deable l'en a trai. $\quad$ (696-697)

La traductora al inglés, Zatta, propone: "He remembered the stag which he had pursued so hard and thought that the devil had taken it" (2005, p. 381; destacado nuestro), entendiendo trai como participio pasado del verbo traire (sacar, tirar, atraer, arrastrar). En nuestra versión, en cambio, interpretamos ese participio como correspondiente al verbo trahir (traicionar, engañar) y traducimos: "Recuerda el ciervo que tanto persiguió, piensa que el diablo así lo ha engañado". 5 Ambas versiones son semánticamente coherentes con los sucesos que conforman el relato. Fundamentamos nuestra elección, no obstante, en el uso corriente, dentro de los textos del período, de la forma trai como participio pretérito de trahir, ${ }^{6}$ así como en la asociación tópica entre la figura demoníaca y el engaño, ampliamente extendida en el imaginario medieval y recogida asimismo en otros pasajes de este y otros poemas hagiográficos presentes en el manuscrito Campsey. ${ }^{7}$

4 En todos los casos en que se citen poemas, las indicaciones entre paréntesis corresponden a los números de versos.

5 Nos referiremos a nuestras decisiones respecto al uso de los tiempos verbales y los conectores en la sección 4 . 6 En cambio, su uso como participio pasado de traire no está testimoniado; antes bien, en otros pasajes del relato se utiliza como participio pasado de este verbo la forma trait (909 y 934). Dentro del paradigma de traire, la forma trai solo está atestiguada como primera persona singular del presente del indicativo, tercera persona singular del pretérito perfecto y segunda persona singular del imperativo.

7 En St. Modwenna, por ejemplo, leemos: "Mai diable ad tun quor trahi" (1302); "Par diable est tuit traiz" (7876). Adviértase que en los tres ejemplos citados el participio aparece escrito de formas ligeramente diferentes. Esta inestabilidad de las grafías y las conjugaciones proyecta una sombra de indeterminación sobre los textos, que habilita lecturas divergentes como las que relevamos para el pasaje bajo consideración. 
La economía y la condensación del francés antiguo contribuyen asimismo a que diversos pasajes resulten ambivalentes, pasibles de recibir distintas traducciones según cómo se los interprete. Por ejemplo:

La contreite s'escrie tant,

Les nerfs li vunt tut crussant,

(1254-1255)

Zatta interpreta que el narrador se refiere a los nervios de los allí presentes, destrozados por los gritos de la mujer ("the crippled woman cried so much that she was shattering all their nerves", 2005, p. 413). Nosotras, que alude a los tendones de las piernas de la propia lisia$\mathrm{da}$, tensados hasta lo insoportable por el milagro que se está obrando en ella ("la lisiada grita tanto, sus tendones están a punto de esta1lar" ${ }^{8}$ ), a semejanza de lo que se relata en otras hagiografías en las que intervienen tullidos. Considérese asimismo este otro pareado:

Mais ele li dist pur nient le fet

Pur nul homme n'ert defet;

$(708-709)^{9}$

Según cómo se comprenda la sintaxis de la frase, puede traducirse "Pero ella le dijo que se esfuerza en vano, que su acción no sería deshecha por ningún hombre", o bien "Pero ella le dijo que lo hecho, por nada, ni por ningún hombre, sería deshecho". El uso registrado de "pur nient le fet", como una expresión semicristalizada con el sentido que explicitamos

8 En el latín de la Edad Media el término nervus se refiere tanto a nervios como a tendones, y esta indeterminación lexical se trasladó a las lenguas vernáculas. Si bien los cirujanos comprendían en la práctica la diferencia entre unos y otros, en los textos suele utilizarse la misma palabra para ambos de manera indistinta (ver al respecto la entrada correspondiente a nerf en el AngloNorman Dictionary (s. f.)).

9 La edición de Russell repone una coma, ausente en el manuscrito, detrás de fet (2005, p. 382). La suprimimos para volver más claro nuestro planteo. en la primera alternativa, podría inclinar la balanza a favor de esta; pero sin embargo no es suficiente para descartar de forma concluyente la segunda. ${ }^{10}$

Fenómenos como los señalados no son en absoluto extraños en los textos medievales. A las probables equivocaciones de los amanuenses y la ambigüedad (cuando no oscuridad) de ciertas formulaciones, hay que añadir otro factor que contribuye a la incertidumbre. Las lenguas medievales son inestables; esto, que es una ley general y afecta incluso al latín (la lengua transmitida por la escuela y la autoridad de los libros), se verifica en un grado mayor en las lenguas vernáculas en el período de su progresiva, y titubeante, emergencia como instrumentos de expresión escrita.

En el siglo XIII, momento de escritura de nuestro texto, ${ }^{11}$ la ortografía, el léxico, la flexión morfológica, la sintaxis de las lenguas vernáculas no estaban fijados ni normativizados. Por el contrario: la variación, tanto en el plano diacrónico como en el sincrónico, es la regla para estas lenguas en las que apenas comenzaba a escribirse. Los diccionarios y las gramáticas con que contamos en la actualidad son posteriores en varios siglos y aproximativos, y fueron confeccionados por estudiosos a partir de los testimonios conservados. No siempre recogen todas las plasmaciones, los matices semánticos o las sutilezas sintácticas que encontramos en los textos. Por supuesto,

10 Si fet estuviera funcionando como sujeto, de acuerdo con la segunda interpretación consignada, el artículo que lo acompaña debería estar declinado en caso sujeto, cuya forma más extendida es li. De todas formas, este no es un criterio concluyente para descartar esta segunda lectura, porque en ocasiones el copista usa le en caso sujeto $(1039,1400,1429,1470)$.

11 Se estima que la Vie seinte Osith fue compuesta hacia fines del siglo XII, pero la versión manuscrita que se conserva data del siglo xiII. 
son herramientas en extremo útiles, pero no necesariamente definitivas.

Otro aspecto que debe tenerse en cuenta es la puntuación. En los textos medievales suele ser caprichosa, reducida al mínimo, cuando no inexistente. Si se la emplea, es de un modo por completo ajeno a las convenciones modernas: en la Vie seinte Osith, por caso, se utiliza un punto para marcar el final de cada verso, aunque la frase continúe en la línea siguiente; no aparece ningún otro signo, aparte de las letras capitales que señalan el comienzo de una nueva sección. ${ }^{12}$ Además, los distintos talleres y escribas usaban a menudo su propio sistema de puntuación particular, diferente a otros. Para favorecer la legibilidad, una traducción debe reponer signos y cortes por lo general ausentes. Según cómo puntúen el texto, las ediciones y las traducciones modernas imprimen ya un principio de interpretación al discurso medieval, y puntuaciones divergentes moldean y permiten comprender de distintas maneras una misma sucesión de palabras. Al traducir estos textos, por lo tanto, y en particular ciertos pasajes potencialmente anfibológicos, conviene sopesar diferentes posibilidades.

Véase por ejemplo cómo cambia el sentido de un pasaje según cómo se lo puntúe:

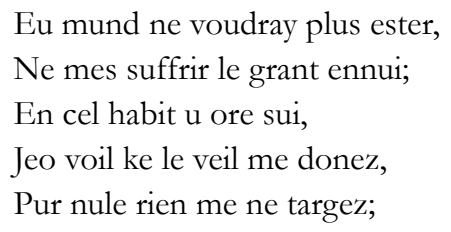

12 Agradecemos a Jocelyn Wogan-Browne y Delbert W. Russell el haber corroborado para nosotras este dato.

13 Damos una traducción cercana a la literalidad para ayudar a la comprensión del pasaje: "En el mundo no querría más estar, / ni más sufrir la gran pesadumbre; / en estos vestidos en que ahora estoy, / quiero que el velo me deis, / por nada me lo aplacéis".
Frente a lo cual, nosotras decidimos leer: "no quisiera ya permanecer en el mundo ni seguir sufriendo su gran pesadumbre en estos vestidos que ahora llevo. Quiero que me deis el velo, no me lo aplacéis por nada". ${ }^{14} \mathrm{La}$ diferente organización de las mismas construcciones por medio de la puntuación desplaza los énfasis y las oposiciones que articulan el pasaje.

Algo similar puede apreciarse en el siguiente fragmento. La edición del poema medieval en su lengua original pone:
Ne puet buche de hume parler,
Oreile oir, ne quer penser,
$\mathrm{Ne}$ oil ver en nule manere
Cum la joie est iluec pleniere
A tuz ceus qui Deu amerunt
E de bon quer le servirunt.
Seinte ${ }^{15}$ Osith nus seit en aye
Tant cum sumes en ceste vie,
Ke tant i puissum bien overer.

(1680-1688)

La traducción al inglés reformula:

Nor may mouth of man tell, ear hear, heart think, or eye see in any way how full is the happiness there.

May St Osith come with help to all those who will love God and serve him with a good heart as long

14 Ampara nuestra decisión la observación de que en el texto anglonormando, por lo general, los pareados (es decir, los dos versos contiguos que comparten la misma rima) se vinculan estrechamente por su sentido y conforman una suerte de unidad semántica. Plasmando una interpretación similar, también Zatta liga los versos 644-645 e introduce un corte a continuación: "I no longer wish to live in the world, or suffer its pains any longer in the clothing I currently wear. I want you to give me the veil. By no means put me off: [...]" (2005, p. 379).

$15 \mathrm{La} \mathbf{S}$ en negrilla corresponde a una letra capital en el manuscrito, destacada a través de la aplicación de tinta roja, la ornamentación y el empleo de un mayor tamaño que en el resto de las letras. 
as we are in this life, so that we may do well... (la frase prosigue; 2005 , p. 439). ${ }^{16}$

A través de la reposición de la puntuación (ausente, como mencionamos, en el manuscrito) se propone una cierta lectura. ${ }^{17}$ Nosotras, por otra parte, resolvimos respetar el corte marcado por la inicial capital, por considerar que su uso no es caprichoso y señala, para el copista, el comienzo de una nueva sección textual:

Ninguna boca de hombre puede contar, oreja oír, ni corazón pensar, ni ojo ver, en ninguna manera, cuán plena será allí la felicidad de todos los que a Dios amen y de buen corazón lo sirvan.

Que Santa Osith nos asista mientras estemos en esta vida, para que podamos obrar bien...

Al igual que Zatta, sin embargo, continuamos esta frase más allá de la puntuación propuesta por Russell en su edición.

Considerada en sus rasgos generales, la retórica medieval es muy diferente a los usos y las preferencias de nuestra contemporaneidad. La fluctuación de los tiempos verbales, la fuerte impronta de la oralidad (no hay que olvidar que estos textos circulaban mayormente de forma oral, y con este fin se concebían ${ }^{18}$ ), el regodeo en las repeticiones, las insistencias, las

16 En pos de la claridad de la exposición, destacamos la letra inicial del nuevo párrafo.

17 Debido a la mayor rigidez relativa del inglés en lo que atañe al orden de los componentes de la oración, en su traducción Zatta reordena los sintagmas para poder ofrecer un texto aceptable en la lengua meta; sin embargo, no debe pasarse por alto que es su intervención en la puntuación lo que determina ese reordenamiento. 18 De hecho, el manuscrito donde se incluye la Vie seinte Osith se destinó — al menos durante un período- a la lectura en voz alta, en las horas de las comidas, en el refectorio del convento de Campsey, según se declara en el propio códice ("ce livere deviseie a la priorie de kanpseie de lire a mengier"). recapitulaciones, los paralelismos, la recombinación de fórmulas, tópicos y motivos manidos, la variación dentro de la reiteración, la redundancia... Estos y otros rasgos similares chocan frecuentemente con la sensibilidad (el oído, el gusto, la norma) actual. Determinar el grado exacto en que se intentará replicar en la traducción estas características (aun a riesgo de ofrecer un texto, en principio al menos, antipático, árido o monótono) o, por el contrario, se procurará atenuarlas en pos de obtener un texto más acorde al horizonte de expectativas y los parámetros literarios del medio meta es una decisión que cabe a los traductores, y que conviene tomar atendiendo al fin de la traducción en cuestión: su propósito, el público al que está dirigida, los ámbitos en que se espera que circule.

Todos los aspectos referidos se subsumen en la que fue, para nosotras, la consideración prioritaria al momento de abordar la traducción: la profunda alteridad que entraña la textualidad medieval para el horizonte de expectativas de nuestro marco social y cultural presente. Debido a una serie de factores, los textos medievales se nos presentan a menudo como más remotos, incluso, que las obras de la antigüedad grecolatina (algo ya observado por Hans Robert Jauss, 1979, p. 187): los usos retóricos, los parámetros compositivos, los modos de

Una de las implicaciones de la modalidad de circulación textual atravesada por la oralidad, propia de los siglos medievales, es que, en muchos aspectos, el sentido de los textos terminaba de completarse en el marco de su declamación, a través de la gestualidad, los tonos de voz o los añadidos de quien los recitaba. El escrito funcionaba como un soporte; en la experiencia total de la recepción textual, esos otros factores - a los que podríamos llamar performáticos — eran de una relevancia determinante. Esta dimensión no-escrita del sentido textual permanece inaccesible para nosotros, lo que sin dudas contribuye a nuestra a menudo imperfecta comprensión de los textos. 
circulación de los discursos, el imaginario, la visión del mundo, los valores son muy otros que los que definen nuestra experiencia. Y sin embargo, es en esta radical otredad que reside su potencial estético y cognoscitivo para los lectores modernos: un potencial que no se nos ofrece, en términos generales, de forma inmediata, sino que solo puede comenzar a desplegarse a través del reconocimiento de esa otredad y el esfuerzo hermenéutico.

En conformidad con estas reflexiones, nos propusimos realizar una traducción que pudiera servir como puente, para los lectores contemporáneos, hacia esa otredad contenida en el relato medieval, es decir, producir un texto que ofreciera una vía de acceso a ese imaginario remoto. Nos planteamos, pues, recrear en la medida de lo posible, ${ }^{19}$ dentro de las alternativas ofrecidas por nuestra lengua castellana de comienzos del siglo XXI, los matices semánticos, las marcas formales, narrativas e ideológicas en que se plasma esa alteridad. Nuestra intención, por lo tanto, fue no aplanar las discordancias sino trasladarlas, exponerlas frente a los ojos de quien se asome al relato a través de la traducción. En la sección 4 nos referiremos con mayor detalle a en qué medida y a través de qué estrategias procuramos llevar a cabo, y plasmar, este propósito. Por el momento, baste con definir en sus rasgos esenciales nuestro abordaje de la labor traductológica como filológico, ${ }^{20}$ puesto que este fue

19 Adoptamos esta precaución de Jean-Louis Fournel y Jean Claude Zancarini (2002, p. 72), que la formulan atendiendo a las consideraciones de Friedrich Schleiermacher acerca de los diferentes modos de traducir: "In my opinion, there are only two possibilities. Either the translator leaves the writer in peace as much as possible and moves the reader toward him; or he leaves the reader in peace as much as possible and moves the writer toward him" (or. 1813; 2012, p. 49 — destacado nuestro—).

20 Puede definirse el objeto de la filología como la tentativa de reconstruir, con la mayor fidelidad posible, el nuestro objetivo fundamental: arribar a una traducción que volviera asequibles, para una audiencia contemporánea mayormente poco familiarizada con la textualidad medieval (y, menos aún, con hagiografías), los efectos de sentido presentes en el texto fuente, así como los procedimientos por los que esos efectos se construyen. $^{21}$

Esto nos lleva a un último punto. Traducir textos producidos en un pasado histórica y culturalmente distante implica, siempre, la dificultad adicional de tener que abrevar en el estudio de ese pasado, cuyo conocimiento no nos es inmediato. Las contribuciones de la filología y de la historia resultan imprescindi-

sentido original de los textos apelando al estudio de la cultura que los produjo. Así concebimos nuestra traducción: como un intento — necesariamente imperfecto y aproximativo- de reconstrucción de un texto remoto, en una lengua, en una cultura y para una audiencia muy diferentes a los originales, a través de los medios que proporcionan la lengua y la cultura de esa audiencia meta y valiéndonos de la metodología y los resultados de la investigación filológica.

21 Remitimos al excelente artículo de Maria Grazia Cammarotta (2018) respecto del rol necesario que desempeña la traducción filológica como medio de acercamiento de los lectores contemporáneos a textos producidos en una cultura remota.

También Fournel y Zancarini, en una serie de trabajos en los que reflexionan sobre su práctica colaborativa como traductores, preconizan un enfoque filológico (Fournel y Zancarini, 2002; Zancarini, 2002; Fournel y Zancarini, 2017). Así, conciben el métier de la traducción como una herramienta que posibilita una lectura inmersiva e iluminadora de las complejidades y dificultades de un texto, y consideran:

il fallait [...] faire sentir, dans le texte traduit, la distance des temps et des langues, qu'il y avait là, dans cet écart, un 'mystère' — pour utiliser le mot de Jérôme — dont il s'agissait de rendre compte mais aussi, d'une certaine façon, de préserver [...] il s'agit bien en effet, dans notre démarche, d'inciter le lecteur français à 'aller à la rencontre' des textes et des auteurs que nous traduisons (Zancarini, 2002, p. 5). 
bles. Para iluminar las connotaciones de una frase, un término, una inflexión, suele ser necesario recurrir a saberes específicos y tan disímiles como, por ejemplo, el contexto político, las tensiones sociales, las controversias religiosas, el sistema discursivo, los usos lingüísticos, las costumbres o los códigos de vestimenta del período, un entramado de factores múltiples y subyacentes que atraviesa y define el imaginario textual. Nuestra intención fue reflejar estas sutilezas en el texto de la traducción; cuando no fue posible o suficiente, por la disparidad de los sistemas de ambas lenguas, recurrimos a la anotación a pie de página (que pretendimos reducir al mínimo, para que no agobie ni interfiera en la lectura) o la introducción. Volveremos sobre este punto en el apartado 5.

\section{Traducir en colaboración}

Como señalan Fournel y Zancarini, tan válida como la pregunta "¿Por qué traducir en equipo?" es su reverso: “¿Por qué no traducir en equipo?” (2017, p. 72). Ateniéndose, sin embargo, al interrogante inicial, la primera respuesta que proporcionan estos autores es de índole política: la cooperación, la amistad intelectual, la resolución de construir un proyecto colectivo constituyen opciones políticas y definen una determinada praxis. La segunda respuesta es más pragmática: la colaboración permite conjugar - y, de esta manera, potenciar- saberes, experiencias y habilidades dispares. De esta articulación se benefician y enriquecen no solo la tarea por realizar, sino también los propios integrantes del equipo, en virtud de la transferencia recíproca de competencias y conocimientos que cimienta el trabajo en común.

Las ventajas concretas que entraña la traducción colaborativa eran reconocidas en la Edad Media. Desde el siglo XII hasta el siglo XVI, la conformación de equipos de traducción fue una práctica extendida en el
Occidente europeo: se reunían diversos especialistas, portadores de distintos saberes y habilidades (intelectuales capaces de hablar y leer diferentes lenguas o versados en distintas ramas del conocimiento, copistas, revisores), para trabajar de forma coordinada. ${ }^{22}$ Fueron emblemáticas en este sentido las prácticas de traducción vinculadas al arzobispado de Toledo y el scriptorium conformado por Alfonso x de Castilla, donde colaboraban cristianos, judíos y musulmanes para trasladar textos latinos, árabes y hebreos al latín y al castellano. A partir del Renacimiento, no obstante, estas prácticas fueron cayendo paulatinamente en el desuso y el descrédito, a medida que cobraban fuerza nociones tales como la autoría singular de los textos y el imperativo de unidad (un proceso que ha sido estudiado por Bistué, 2013). E1 Romanticismo, con su exaltación del genio solitario, profundizó esta tendencia, de la que somos en buena medida herederos.

Y sin embargo, ¿por qué no trabajar en equipo? En las últimas décadas, la proliferación de experiencias colaborativas en el campo de la traducción se ha visto favorecida, entre otros factores, por el desarrollo de nuevas herramientas digitales, la difusión de diversas formas de crowdsourcing o la constitución de proyectos académicos grupales, en muchos casos interdisciplinarios. Paralelamente, los estudios sobre traducción manifiestan un interés renovado por las dinámicas colaborativas, sus posibilidades y sus condiciones, prueba de lo cual es un número creciente de publicaciones que abordan el asunto desde perspectivas teóricas, históricas o prácticas. ${ }^{23}$

22 Sobre estas dinámicas colaborativas en la Baja Edad Media pueden consultarse: Menéndez Pidal, 1951; D’Alverny, 1989; Bistué, 2013, pp. 23 y ss.

23 Un relevo exhaustivo excedería los límites y el foco de este artículo. Remitimos, pues, al panorama propor- 
En nuestro caso particular, nos seducía la posibilidad de ensayar otra lógica de trabajo y otro modo de acercamiento al texto, diferentes de aquellos a los que, por nuestra formación y nuestros derroteros, estamos más habituadas: la lectura y la interpretación individuales, la labor solitaria. Por otra parte, estábamos convencidas de que nuestros intereses, conocimientos y experiencias personales, con varios puntos de coincidencia, pero asimismo divergentes, podían complementarse de manera tal de enriquecer la tarea, sus resultados y a nosotras mismas, que terminaríamos aprendiendo, una de la otra, y juntas a lo largo del proceso. Decidimos, pues, abordar la traducción de forma colaborativa, asumiendo que esta dinámica nos brindaría más y mejores herramientas para afrontar los desafíos propios de la textualidad medieval antes señalados.

Traducir de a dos, descubrimos, implica acordar criterios, considerar soluciones posibles que por separado no se nos hubieran ocurrido, ver iluminarse (u oscurecerse) súbitamente un pasaje a través de la mirada ajena, sopesar a conciencia - línea a línea-diversas alternativas, debatir opciones, argumentar, retractarse, verse en la necesidad de explicitar y fundamentar asunciones que en la labor solitaria solemos dar por sentadas sin haberlas sometido tal vez nunca a examen. El diálogo sostenido que supone el trabajo colaborativo fuerza a volver conscientes, y objetos de revisión constante, procedimientos que de otra manera tendemos a automatizar, ensancha la comprensión individual del texto fuente (especialmente cuando se trata de textos, como los medievales, que entrañan dificultades interpretativas particulares) y amplía el abanico de soluciones posibles en la lengua meta. No hay dudas de que el cruce de perspectivas resultó

cionado por el volumen compilado por Cordingley y Frigau (2017). sumamente fecundo para nuestro proceso de trabajo; confiamos en que también para sus resultados.

Cada texto, se sabe, presenta una conformación particular, que determina la labor de la traducción. A esto se sumó el reto adicional de establecer principios claros y un método de trabajo común que nos permitiesen desarrollar esa labor: descubrirlos, construirlos, refinarlos en el proceso, puesto que nunca antes habíamos emprendido una traducción colaborativa. A medida que avanzamos en la tarea debimos, por lo tanto, avanzar paralelamente en la invención de una metodología y una dinámica que se acordaran a las singularidades planteadas por el texto, así como a nuestras necesidades e inclinaciones. Abordaremos este aspecto a continuación.

\section{Estrategias de traducción}

\subsection{Justificación de la selección del texto: la Vie seinte Osith como señuelo}

La decisión de traducir la Vie seinte Osith fue motivada por la identificación de un vacío notorio en el campo de las traducciones de textos medievales al castellano: a pesar de la inmensa cantidad de obras hagiográficas conservadas en francés antiguo y en otras lenguas no hispánicas del Occidente medieval, solo un número muy reducido se ha traducido al castellano. ${ }^{24}$ De manera que un lector sin una experticia específica en estas lenguas solo puede acceder a un conocimiento parcial y sumamente distorsionado del sistema textual de la Edad Media europea. Una evaluación de los

24 La única traducción que ha alcanzado una amplia circulación en el ámbito hispanoparlante es el Viaje de San Brandán (Lemarchand, trad., 1983), un poema anglonormando de inicios del siglo xII, en verdad muy poco representativo del género hagiográfico. 
catálogos de las principales editoriales hispanoparlantes que publican textos medievales traducidos revela que se tiende a optar por obras que se ajustan en forma más clara a una concepción moderna de la literatura, entendida como una práctica secular y autónoma, ${ }^{25}$ criterio que excluye una porción significativa de la producción medieval, incluidas las vidas de santos. La traducción de la Vie seinte Osith tuvo, entonces, como propósito central introducir la hagiografía en el ámbito literario hispanoparlante y, de esta forma, contribuir a ofrecer una imagen más amplia y representativa de la textualidad medieval.

Ahora bien, la resistencia que suscita el género hagiográfico no es, conviene aclararlo, una característica privativa de los modos de lectura de la literatura medieval en Hispanoamérica, sino que constituye un indicio de un fenómeno más amplio. En el proceso de recepción moderna de la narrativa medieval se ha tendido a desplazar la hagiografía de su lugar histórico-cultural como uno de los géneros centrales de las literaturas vernáculas de la Edad Media. En consecuencia, los relatos de santos, dominantes en el contexto de su primera recepción, apenas si tienen lugar en el imaginario contemporáneo de la narrativa medieval, constituido más bien a partir de las grandes gestas heroicas o las historias de amor y de caballería.

25 Michel Zink (1999) describe con precisión los problemas que plantea el uso del término "literatura" para hacer referencia a la textualidad medieval. Según señala, durante la Edad Media el arte de la escritura se aplica por igual a todas las disciplinas del conocimiento. En consecuencia, el espacio de las letras no se encuentra reservado únicamente a los textos en los que es posible reconocer una búsqueda estética o un desarrollo ficcional, sino que incluye también una amplia variedad de producciones, desde cantares de gesta o novelas hasta herbarios, bestiarios y textos científicos.
Estas consideraciones sobre la recepción moderna de la hagiografía y sobre los criterios que, hasta el presente, han guiado la selección de los textos traducidos al castellano tuvieron una marcada incidencia en la elección del texto hagiográfico específico que decidimos abordar. El personaje de santa Osith está basado en la leyenda pseudohistórica de una princesa de la Inglaterra anglosajona que, tras huir de un matrimonio indeseado y tomar los hábitos, habría fundado un monasterio en Chich, al este de Inglaterra, donde sufre el martirio en el contexto de una de las invasiones vikingas de las islas británicas. Si bien Osith ocupa un lugar marginal en el panteón de la Iglesia cristiana, ${ }^{26}$ la narración de su vida comparte con los relatos seculares más difundidos un conjunto de rasgos cuyo reconocimiento permitiría al lector atenuar la reticencia que suele suscitar la primera aproximación a este género y su ideología. A diferencia de otras vidas de santos del período, de una fuerte impronta argumentativa y doctrinaria, la Vie seinte Osith se constituye como un texto esencialmente narrativo, que refiere en forma ágil y dinámica una serie de eventos de naturaleza extraordinaria que tienen lugar, en parte, en un marco aristocrático y cortesano. Esta caracterización general del texto podría aplicarse sin mayores inconvenientes a los relatos caballerescos más canónicos, cuya lectura ha modelado, como señalamos, la concepción moderna más extendida de la literatura medieval. ${ }^{27}$ En este

$26 \mathrm{El}$ propio autor de la Vie reconoce en su prólogo la marginalidad de la leyenda y se lamenta porque la historia de santa Osith “n'estut guerres leue, / ne cum dreit fust par tut seue" (67-68; "no es muy leída ni es conocida en todas partes, como debería").

27 De hecho, uno de los episodios centrales del relato, la huida del matrimonio por parte de santa Osith y su consagración, se articula a partir del motivo de la caza del ciervo blanco, motivo que se incluye asimismo en el roman artúrico de Erec et Enide, de Chrétien de Troyes (Fritz, ed. y trad., 1992), o los lais de Guigemar, de Marie 
sentido, Osith se reveló como una suerte de senuelo a partir del cual resultaría posible atraer el interés de un lector familiarizado con otros géneros de la literatura de la época y, al mismo tiempo, ampliar su horizonte de expectativas a ciertos aspectos de la hagiografía que quizá resulten más difíciles de asimilar, puesto que acusan de manera más notoria la distancia que nos separa del universo evocado por el relato.

\subsection{Método del trabajo en colaboración}

La distancia de más de ocho siglos que se interpone entre el momento de la escritura y el de nuestra recepción condicionó en numerosos aspectos nuestro método de trabajo: la textualidad medieval, como se desprende de la caracterización que ofrecimos, exige la incorporación de algunas tareas filológicas específicas para las que se requieren materiales también específicos e impone un ritmo particular al desarrollo de la labor de traducción. Al optar por traducir en colaboración debimos explicitar, analizar y consensuar la forma en que desarrollaríamos actividades que, al trabajar por separado, solemos naturalizar o automatizar. Esas reflexiones resultaron en la elaboración de un método colaborativo de trabajo que describiremos paso a paso, ya que fue en el curso de su implementación que fuimos dando forma a los fundamentos de nuestra práctica.

La traducción estuvo a nuestro cargo, dos medievalistas con intereses comunes y formaciones en buena medida complementarias que, combinadas, nos permitieron abordar los

de France, y Tyolet (Koble y Séguy, eds., 2011), relatos seculares aproximadamente contemporáneos a nuestro poema que la historia literaria francesa ha colocado en el centro del canon medieval. Este motivo gozó, asimismo, de una enorme fortuna en otras literaturas vernáculas del Occidente medieval. problemas filológicos y exegéticos que plantea la Vie seinte Osith. Durante el desarrollo del proyecto, la colaboración alcanzó también a otros actores que, en función de sus competencias específicas, tuvieron distintos grados de participación en una u otra etapa: colaboración en la dilucidación de pasajes puntuales del texto fuente, consultas lexicales, revisiones preliminares, lecturas de prueba, edición, etc. Sin embargo, en el marco de este estudio nos referiremos a la traducción colaborativa definida en su sentido más restringido, como la colaboración "regular o sistemática" de dos o más personas en la ejecución integral de un proyecto (Vanderschelden, 1998, p. 23). ${ }^{28}$ Así entendida, la colaboración se circunscribió entonces a dos cotraductoras, con idéntico compromiso, participación y responsabilidad. La horizontalidad de nuestras posiciones relativas en el proyecto fue, sin duda, la clave de nuestra colaboración.

Como primer paso, acordamos algunos criterios de traducción que, en un principio, elaboramos a partir de la reflexión sobre nuestras experiencias previas en la producción y la lectura de traducciones modernas de textos medievales. Describiremos en el próximo apartado las vicisitudes de nuestra relación con estas aspiraciones preliminares; baste, por ahora, señalar que el cumplimiento de este paso nos permitió sentar las bases de una dinámica de trabajo cuyo eje fue el control de la coheren-

28 Isabelle Vanderschelden se refiere, en verdad, al caso particular de la colaboración entre autores y sus traductores, pero sus conclusiones fueron recogidas más recientemente por Anthony Cordingley y Céline Frigau Manning en una reflexión sobre el alcance y los límites del concepto de traducción colaborativa: "Indeed, there are evidently different degrees of collaboration between different agents in the continuum of the collaborative processes that accompany the publication and reception of a translation, some justifying claims to co-translatorship, others not" (2006, p. 24). 
cia y la consistencia de nuestras decisiones a lo largo del desarrollo del proyecto. Establecidos, pues, estos criterios, avanzamos hacia la elaboración de nuestra primera versión.

En esta etapa, la colaboración se llevó a cabo mediante la alternancia entre instancias de trabajo individual y encuentros reservados a la revisión y el debate. Traducir un texto en una lengua antigua es una tarea lenta y trabada que procede a partir de la investigación minuciosa de términos, giros o estructuras sintácticas que no siempre resultan transparentes en una primera lectura. La fijación de su sentido exige, por lo tanto, consultar de manera regular una cantidad significativa de recursos auxiliares, como glosarios, diccionarios, gramáticas, otros textos del período y sus traducciones modernas, bibliografía complementaria, inclusive mapas e imágenes. La división de esta labor exhaustiva de investigación fue una de las estrategias que le otorgó mayor fluidez a nuestro trabajo. En esta primera etapa, entonces, nos distribuimos fragmentos sucesivos de alrededor de cien versos y pautamos reuniones semanales para revisar el total de los doscientos versos que entre las dos habíamos traducido. Despejado el grueso del trabajo de búsqueda y consulta que requiere la primera aproximación a la fuente, en nuestros encuentros nos dedicamos a investigar problemas que no habíamos podido resolver en forma individual y a corroborar o corregir nuestras propuestas mediante la revisión conjunta del fragmento que cada una había aportado. Esta revisión consistió en la lectura en voz alta del texto en castellano por parte de la persona responsable del segmento, mientras que la otra cotejaba la traducción que oía con el texto anglonormando, verso por verso. En el caso de los pasajes que presentaban mayor complejidad o se prestaban a más de una interpretación, examinábamos y discutíamos distintas alternativas de traducción que habíamos concebido.
Realizar este paso de a dos fue sumamente provechoso por varias razones: en principio, porque nos permitió duplicar la vigilancia sobre el proceso de traducción, a fin de evitar saltos u otros errores, los cuales eran detectados con más facilidad por quien no había estado a cargo del fragmento y podía ofrecer una mirada renovada sobre el texto. Pero más allá de este cotejo a un nivel más elemental, escuchar la vida de santa Osith en castellano por primera vez nos llevó a situarnos en el lugar del receptor y, desde esa posición, a reevaluar la pertinencia o la viabilidad de algunos de los criterios que habíamos fijado de antemano en forma abstracta.

Esta dinámica de traducción y revisión por fragmentos se repitió semanalmente hasta obtener la primera versión completa del texto en castellano. Para el siguiente paso, orientado a la revisión de esta traducción más bien experimental, invertimos la asignación de los fragmentos, de modo que cada cual trabajó sobre los pasajes que en el paso anterior habían estado a cargo de su compañera. Este segundo paso no siguió de manera inmediata al primero, sino que, entre uno y otro, intercalamos un período de desconexión absoluta con respecto a la traducción, a fin de despejar nuestra mirada, volverla más sensible a posibles inadvertencias o errores $\mathrm{y}$, sobre todo, evitar los condicionamientos a los que puede inducir el contacto estrecho y repetido con el texto. La revisión se llevó a cabo mediante la misma dinámica: de una semana a otra editamos individualmente fragmento por fragmento, utilizando la herramienta de control de cambios del procesador de texto para poder visualizar las modificaciones propuestas. El espacio de nuestras reuniones se utilizó, al igual que en el paso anterior, para evaluar la pertinencia de las correcciones por medio de la lectura en voz alta y el cotejo con la fuente. En esta etapa terminamos de definir la forma en que 
utilizaríamos los paratextos, seleccionando la información que colocaríamos en el prólogo y fijando los puntos en que insertaríamos notas explicativas, ya fuera sobre cuestiones histórico-culturales o sobre problemas específicos de la traducción.

Transcurrido un nuevo intervalo de distanciamiento con respecto al texto, emprendimos el tercer paso, que consistió en la revisión integral de la traducción. Respetando en líneas generales el sentido al que habíamos arribado en los pasos previos, más marcadamente exegéticos, en esta etapa nos enfocamos en la dimensión formal de nuestro texto castellano. Con este objetivo, sustituimos el cotejo verso por verso, que había organizado nuestras revisiones previas, por la lectura en voz alta de unidades textuales más amplias de nuestra versión de La vida de Santa Osith: mientras una leía un párrafo, la otra tomaba notas para luego hacer propuestas sobre el pasaje; la que había leído apuntaba sugerencias también. Este abordaje nos proporcionó una visión más panorámica de nuestro trabajo y puso en primer plano aspectos de la traducción que las lecturas tan meticulosas como entrecortadas realizadas en las instancias previas no habían revelado. Fue, por ejemplo, en esta instancia que tomamos plena conciencia del efecto acumulativo de ciertas repeticiones de términos o expresiones y que ajustamos la puntuación en consideración del ritmo de la prosa castellana.

Para el último paso, convocamos a un número de lectores de prueba con distintas formaciones y especialidades para que, en función de sus experticias y competencias individuales, evaluaran y comentaran nuestro trabajo. Debido a la variedad de los enfoques asumidos por los lectores, las devoluciones que recibimos fueron de enorme interés y nos permitieron obtener una suerte de diagnóstico sobre la precisión, la coherencia y la legibilidad de nuestra traducción.

Solo al cabo de este último paso y como resultado de un movimiento pendular ininterrumpido entre la teoría y la práctica alcanzamos una versión definitiva de nuestros criterios de traducción. El próximo apartado expone y fundamenta algunas de las conclusiones más relevantes de ese recorrido, extenso y sinuoso, que seguimos entre nuestras ideas preliminares y las decisiones que terminamos adoptando en el desarrollo del proceso que acabamos de describir.

\section{Criterios de traducción}

A lo largo de las sucesivas instancias de nuestra metodología de trabajo, sostuvimos una serie de debates sobre distintos niveles del texto (léxico, semántico, sintáctico, retórico) y sobre la forma de la eventual publicación (paratextos, diagramación, presentación). A continuación, nos detendremos en estos diversos aspectos y las resoluciones particulares a las que arribamos en cada caso, atendiendo siempre a la que ya señalamos como nuestra determinación prioritaria: recrear, en la medida de lo posible, la alteridad propia del texto medieval. Esta premisa nos condujo, como se verá, a combinar un conjunto de estrategias diferenciadas pero solidarias entre sí: a fin de poder mantener y hacer manifiesta esa otredad en ciertos planos textuales que elegimos privilegiar -i.e., las connotaciones lexicales, los matices semánticos, así como determinados rasgos retóricos que consideraremos en los próximos párrafos-, debimos abreviar esa distancia y extrañeza en otros niveles, de manera tal de poder recrear con mayor fidelidad los aspectos privilegiados y evitar, por otra parte, caer en la ilegibilidad o la aridez insalvable. Procederemos en esta revisión avanzando de lo más general a lo más puntual. 
Nuestra intención fue ofrecer una traducción que oficiara como un puente, una vía de acceso, al texto medieval. Por consiguiente, decidimos desde el principio que la edición a la que apuntaríamos sería bilingüe, con una diagramación que contrastase, en páginas enfrentadas, el texto original con nuestra versión. Saber que los futuros lectores contarían con esta información claramente expuesta repercutió en otras decisiones que debimos tomar.

Nos alentó, por ejemplo, en nuestra resolución de prosificar el relato. El poema francés está escrito en versos octosílabos pareados; intentar mantener la métrica nos hubiera forzado a sacrificar mucho del contenido, y algo similar hubiera ocurrido con otras soluciones intermedias de compromiso que hubiéramos podido ensayar, como es el verso libre. La plasticidad de la prosa nos permitió acercarnos a los efectos de sentido y las construcciones sintácticas del original sin mayores restricciones formales. Los lectores curiosos podrán apreciar la forma y la musicalidad intransferibles del original en la página contrapuesta, guiándose con la traducción castellana.

En cuanto a los paratextos, preferimos reducir la anotación a pie de página al mínimo indispensable para que no interfiriese con la lectura, y circunscribirla por ejemplo a aclarar el significado de términos inhabituales (como puede ser el caso de ciertas unidades de longitud en desuso), señalar fragmentos oscuros o de dudosa resolución o brindar la interpretación alternativa de pasajes ambiguos en el original. En cambio, resolvimos reservar al estudio introductorio la identificación de personajes históricos y topónimos, junto a otros aspectos histórico-culturales que contribuyen a una comprensión más profunda y cabal del universo narrativo.
Como ya mencionamos, la oscilación pendular entre nuestras ideas (tanto las preliminares como las sucesivas) y el progreso en la tarea concreta de la traducción, es decir, la dialéctica necesaria entre la teoría y la práctica, nos llevó a afinar progresivamente nuestros criterios. El plano en el que más claramente se plasmó esta mutación, sin duda saludable, fue nuestra postura con respecto a la sintaxis. En un principio nos propusimos respetar a rajatabla la organización sintáctica del texto fuente. En esta línea, mantuvimos los paralelismos, la parataxis, los polisíndeton y la sobreabundancia general de nexos coordinantes, fenómenos característicos de la escritura medieval; solo utilizamos subordinadas cuando el original lo hacía. Sin embargo, a medida que avanzamos en la labor, consideramos que una fidelidad excesiva en lo relativo al orden de los sintagmas dentro de la oración supondría un estorbo de nulo provecho para el lector, por lo que decidimos relajar este criterio. Además, el orden sintagmático en el poema francés está en buena medida determinado por las exigencias métricas; habiendo abolido estas, no tenía demasiada justificación respetar ciertos hipérbatos. Los cambios que indujo la flexibilización de este criterio pueden apreciarse al comparar dos versiones de un mismo pasaje. Nuestra primera traducción, más apegada al original, leía:

El viento era fuerte y muy tempestuoso, las faldas de su manto arranca, pero por los broches en el cuello quedó prendido. Y por los pliegues contra su cuerpo recogió el manto y al hacerlo el libro olvidó, que de sus manos al agua cayó. Por esta pérdida quedó consternada, para agarrarlo se inclinó y lo siguió; creyó su libro haber recuperado pero a ambos el río capturó. ${ }^{29}$

Decidimos en una segunda instancia no ser tan rigurosas con respecto al orden sintagmático,

29 El pasaje corresponde a los versos 279-288. 
a fin de aproximarlo a usos más habituales del castellano actual y suavizar así lo que constituiría un escollo adicional para la lectura:

El viento era fuerte y muy tempestuoso y arranca las faldas de su manto, pero este quedó prendido de los broches en el cuello. Y ella recogió los pliegues del manto contra su cuerpo y al hacerlo olvidó el libro, que cayó de sus manos al agua. Quedó consternada por esta pérdida. Se inclinó para agarrarlo y lo siguió; creyó haber recuperado su libro, pero el río los capturó a ambos.

Una vez más, presentar el poema original junto a la traducción nos brindaba un extra de libertad en este sentido: las particularidades sintácticas se ofrecen al alcance del lector dispuesto a realizar una lectura contrastada, sin lastrar innecesariamente el texto castellano. De todas maneras, incluso si no se hubiese tratado de un proyecto de edición bilingüe habríamos optado por este criterio de relativa flexibilidad sintagmática, en pos de una legibilidad más amable.

Otro aspecto en el que se enfocaron nuestros debates fue el tratamiento de las repeticiones, que, como señalamos en la introducción, abundan en los textos medievales. Se repiten vocablos, fórmulas, interpelaciones a la audiencia y, en ocasiones, oraciones enteras. En términos generales, y a riesgo de irritar la sensibilidad de los lectores habituados a las pautas de estilo del castellano contemporáneo, tendimos a mantenerlas, evitando emplear sinónimos que hubieran traicionado la austeridad léxica del texto francés. Nos permitimos, sin embargo, cierta flexibilidad en el tratamiento de las fórmulas de aseveración, como pur veir (en verdad, por cierto), variándolas o, a veces, omitiéndolas, cuando es evidente que su utilización había sido forzada por la rima.
En el nivel morfológico, una de las características quizá más desconcertantes de los relatos en verso escritos en francés antiguo es la denominada "confusión" de los tiempos (Ollier, 1978): con frecuencia, en el marco de un episodio o, incluso, en la unidad mínima del verso, los tiempos verbales alternan entre distintas formas del pasado (pretérito simple, pretérito compuesto, pretérito imperfecto) y el presente. Este fenómeno es recurrente en la Vie seinte Osith y adquiere mayor prominencia en los momentos más dramáticos del relato, como el martirio de la santa:

$\begin{array}{ll}\begin{array}{l}\text { Seinte Osith fu le jur alee } \\ \text { Si cum esteit acustumee, }\end{array} & \begin{array}{l}\text { pretérito compuesto } \\ \text { A une secree fontaine }\end{array} \\ \begin{array}{l}\text { Quatre meschines ou sei meine, } \\ \text { Pur sei laver sunt alees }\end{array} & \text { presente } \\ \text { E li paen les unt trovees; } & \text { pretérito compuesto } \\ \text { N'entendirent } \text { pas lungement } & \text { pretérito compuesto } \\ \text { Ainz decolent communaument } & \text { presente } \\ \text { Seinte Osith ke unt trové ci } & \text { pretérito compuesto } \\ \text { E les autres ensemble ou li. } & \\ \text { Mes Seinte Osith tut erranment } & \\ \text { Son chief entre ses mains prent, } & \text { presente } \\ \text { Si cum n'eut anguisse eue, } & \text { pretérito anterior } \\ \text { Tant veit k'al muster } \text { est venue... } & \text { presente / pretérito } \\ \text { (798-811; destacados nuestros) } & \text { compuesto }\end{array}$

Ese día, como era su costumbre, Santa Osith fue hasta una fuente secreta; lleva consigo a cuatro muchachas. Habian ido para bañarse y los paganos las encontraron. No se demoraron mucho sino que las decapitan a todas, a Santa Osith, a quien encontraron allí, y a las otras junto a ella. Pero Santa Osith toma de inmediato su cabeza entre las manos, como si no bubiese sufrido ningún daño, y camina hasta llegar al monasterio.

En nuestra traducción nos propusimos respetar la alternancia de las formas verbales, en la medida en que la gramática castellana lo permite, para evitar otorgarle a la narración una linealidad y una homogeneidad que en su lengua original no tiene. Esta decisión se fundamenta, además, en el potencial semántico y expresivo que implica la repentina actua- 
lización de los sucesos que se están relatando. En el pasaje citado, por ejemplo, el salto del pasado al presente acentúa, mediante el contraste, las acciones que dicen el martirio de Osith y el milagro que sucede a su decapitación. ${ }^{30}$ Es cierto que, en ocasiones, estas oscilaciones podrían explicarse, simplemente, por necesidades métricas o de la rima, y no encierran tales efectos escenográficos asociados con "une poétique du surgissement", como la denominan Nathalie Koble y Mireille Séguy (2011, p. 138). Sin embargo, hemos preferido mantener los juegos verbales a fin de dejar que el lector sopese y analice por sí mismo su significación relativa en los distintos pasajes en los que aparecen.

Un problema similar, aunque más difícil de explicar (Foulet, 1923, pp. 144 y ss., Ménard, 1968 , p. 39), plantea la oscilación entre las formas pronominales y verbales utilizadas por un personaje para dirigirse a un mismo interlocutor. Documentado con frecuencia en los textos en francés antiguo, este fenómeno no escapa a la Vie seinte Osith. Aparece de manera notoria en el diálogo entre una lisiada y san Edmundo, quien se aparece milagrosamente a la mujer en respuesta a sus rezos. Mientras que en este intercambio la lisiada se dirige al santo de manera uniforme mediante la segunda persona del plural, asociada con el tratamiento de respeto ( $v u s$ ), san Edmundo, en cambio, alterna entre el tu y el vus en los tres parlamentos que se le atribuyen y, asimismo, en el seno de una misma interpelación:

30 En su estudio sobre los tiempos verbales en la obra de Chrétien de Troyes, Marie-Louise Ollier explica esta alternancia verbal por el lugar que todavía tiene la oralidad en los romans en verso. Señala la especialista que el presente del relato es, en verdad, el presente de la voz que inscribe en el pasado de la historia (1978, p. 105). Esta propuesta es retomada y desarrollada por Zumthor (1989).

\author{
"Diva!" ceo dit, "Ki es tu ci \\ Ke tute nuit me cries si? \\ Ke demander, ke vus aveir?" \\ tacados nuestros) \\ “Vamos!”, dijo él, “¿quién eres tú que me invocas así \\ toda la noche? ¿Qué pedís, qué deseáis obtener?”
}

En su siguiente alocución, vuelve a la segunda persona del singular (1153-1159) y en la última, se decanta por el vus (1172-1177). Los filólogos no han dejado de señalar la paradoja que entraña el hecho de que una sociedad sumamente consciente de las jerarquías revele, a través de sus testimonios escritos, un uso tan errático de las fórmulas de tratamiento (Lebsanft, 1987). Esta inconstancia atenta contra la posibilidad de reconstruir de modo certero los matices retóricos o semánticos que la audiencia medieval atribuía a las distintas formas de tratamiento, con lo cual sería muy aventurado explicar las razones del pasaje repentino de una a otra. Lucien Foulet y Philippe Ménard, de hecho, registran un número de ejemplos en los que la alternancia no exhibe realmente una intención particular (Foulet, 1923; Ménard, 1968, p. 39). De cualquier forma, en lugar de ahorrarle al lector estas "bizarreries déconcertantes", como las califica Foulet (1923, p. 146), decidimos mantenerlas, ya que constituyen uno de los pocos indicios de la inestabilidad del francés antiguo que es posible traducir al castellano.

En lo que atañe al nivel lexical, evitamos sistemáticamente términos que pudieran resultar modernos o anacrónicos, bien por su historia o por las asociaciones que despiertan en nuestro imaginario. Procuramos no violentar, en este plano, la distancia que nos separa del mundo del relato. No recurrimos, sin embargo, a arcaísmos que forzaran esa lejanía.

El estudio de diversos aspectos de la cultura medieval y la frecuentación de otros textos del período nos guiaron en la búsqueda de equiva- 
lentes aproximados para términos y expresiones que no tienen un paralelo exacto en nuestra lengua. Uno de los desafíos que se nos presentaron en este sentido fue el término vertu, empleado extensamente a lo largo del poema, a menudo dentro del par miracles e vertu. El espectro semántico que condensa la palabra ver$t u$ es amplio: fuerza física, poder, capacidad, potencia, milagro, virtud, excelencia moral... Ningún término del castellano medieval o posterior reúne todos estos matices y acepciones, latentes en la palabra francesa. La traducción debería ser, necesariamente, parcial. Una dificultad adicional se planteaba: la acepción dominante en la mayoría de las ocurrencias de la palabra dentro del poema es la de milagro; sin embargo, al encontrarse dentro de la dupla miracles e vertu, no podíamos traducirla de esa manera. Optamos al fin por traducir esta pareja como "milagros y prodigios", ya que el significado de este término ("suceso extraño que excede los límites regulares de la naturaleza") lo aproxima a la concepción cristiana del acontecimiento milagroso, al punto de que su tercera acepción es, precisamente, la de "milagro" o "hecho de origen divino";31 "prodigios" nos permitió, por lo tanto, remedar en nuestra lengua la virtual redundancia de la expresión francesa. Descartamos, en cambio, traducirlo como "maravillas" (la alternativa provista por los diccionarios ${ }^{32}$ ) por remitir esta palabra a un repertorio del imaginario medieval más amplio y no del todo coincidente con el del milagro, ${ }^{33}$ y por conllevar muy fuertemente

31 Real Academia Española. (2018). Prodigio. En Diccionario de la lengua española (versión electrónica 23.2). Recuperado de https://dle.rae.es/?id=UGmwpRG; consultado el 25 de abril de 2019.

32 Ver, por ejemplo, la entrada correspondiente a vertu en el Anglo-Norman Dictionary: http://www.anglo-norman.net/D/vertu; consultado el 25 de abril de 2019.

33 Sobre esta cuestión, que desborda los propósitos de este artículo, remitimos al clásico trabajo de Jacques Le Goff "Lo maravilloso en el Occidente medieval" (1985). la connotación de suceso o cosa que provoca maravilla y admiración, un rasgo no implicado en el concepto de vertu.

\section{Conclusiones. Expandir lo traducible a través de lo traducido}

En las secciones previas nos propusimos describir nuestra experiencia de traducción colaborativa, abordándola desde una serie de ángulos: los desafíos planteados por la textualidad medieval, las consideraciones que guiaron la selección del texto, la metodología de trabajo en equipo a la que arribamos, los beneficios de la colaboración, los criterios que adoptamos en la elaboración de nuestra versión. Para concluir, quisiéramos volver sobre las motivaciones que impulsaron, en primer lugar, la traducción, y sus proyecciones ulteriores a partir de la tarea ya realizada.

En cada una de sus instancias, nuestro trabajo estuvo determinado, como señalamos, por una regla prioritaria: recrear, en la medida de lo posible, la alteridad inherente al texto medieval, de manera tal de poder darle acogida y volverla legible, en el más amplio sentido del término, dentro de nuestro horizonte argentino e hispanoamericano. En el contexto de nuestro medio cultural, concebimos la traducción de La vida de Santa Osith como señuelo y punta de lanza, que pueda conducir no solo a un mejor conocimiento de la ingente producción hagiográfica de los siglos medios $\mathrm{y}$, por extensión, de su sistema textual entero, sino también a generar el interés y las condiciones para que puedan surgir, eventualmente, otras traducciones de este género tan poco explorado. Confiamos en la capacidad de la traducción de iluminar nuevos focos de legibilidad y señalar caminos por descubrir. Por nuestra parte, nos proponemos seguir desarrollando la dinámica de trabajo que logramos definir en el proceso de la colaboración y trasladar- 
la a otras traducciones en esta misma línea de investigación.

\section{Referencias}

Anglo-Norman dictionary. Consultado en http://www.anglo-norman.net/

Baker, A. T. (ed.) (1911). An Anglo-French Life of St Osith. Modern Language Review, 6(4), 476-502. Recuperado de https:// www.jstor.org/stable/3713283

Baker A. T. y Bell, A. (eds.) (1947). Sainte Modwenna. En ANTS (vol. 7). Oxford: Blackwell.

Bistué, B. (2013). Collaborative practices, multi-version texts and the difficulty of thinking translation. En Collaborative translation and multi-version texts in early modern Europe (pp. 1-17). Burlington: Ashgate.

Cammarota, M. G. (2018). Translating medieval texts. Common issues and specific challenges. Filologie Medievali e Moderne, 17(14), 37-53. Recuperado de https:// edizionicafoscari.unive.it/en/edizioni/ libri/978-88-6969-250-5/translating-medieval-texts/

Cerquiglini, B. (1989). Éloge de la variante : histoire critique de la philologie. París: Seuil.

Chrétien de Troyes (1992). Erec et Enide. (J-M. Fritz, ed. y trad.). París: Le Livre de Poche.

Cordingley, A. y Frigau Manning, C. (2017). What is collaborative translation? En A. Cordingley y C. Frigau Manning (Eds.), Collaborative translation: From the Renaissance to the Digital Age (pp. 1-30). Londres: Bloomsbury.

Cordingley, A. y Frigau Manning, C. (eds.) (2017). Collaborative Translation: From the Renaissance to the Digital Age. Londres: Bloomsbury.

D'Alverny, M-T. (1989). Les traductions à deux interprètes: d'arabe en langue vernaculaire et de langue vernaculaire en latin. En G. Contamine (ed.), Traductions et traducteurs au Moyen Âge. Actes du colloque international du cnrs organisé à Paris, Institut de recherche et d'histoire des textes, les 26-28 mai 1986 (pp. 193-208). París: Éditions du CNRS.

Foulet, L. (1923). Petite syntaxe de l'ancien francais. París: CFMA.

Fournel, J-L. y Zancarini, J-C. (2002). Les enjeux de la traduction [Traduire les penseurs politiques florentins de l'époque des guerres d'Italie]. Actes de la recherche en sciences sociales, 145, La circulation internationale des idées, 84-94. Recuperado de https://www.persee.fr/doc/arss_03355322_2002_num_145_1_2801

Fournel, J-L. y Zancarini, J-C. (2017). For a practice-theory of translation: On our translations of Savonarola, Machiavelli, Guicciardini and their effects. En A. Cordingley y C. Frigau Manning (eds.), Collaborative translation: From the Renaissance to the Digital Age (pp. 68-88). Londres: Bloomsbury.

Jauss, H. R. (1979). The alterity and modernity of medieval literature. New Literary History, 10(2), 181-229. Recuperado de https://www.jstor.org/stable/468759

Koble, N. y Séguy, M. (eds.) (2011). Lais Bretons. París: Champion.

Lebsanft, F. (1987). Le problème du mélange $\mathrm{du}$ « $\mathrm{tu}$ » et $\mathrm{du}$ « vous » en ancien français. Romania, 108(429), 1-19. Recuperado de https://www.persee.fr/doc/roma_00358029_1987_num_108_429_1818

Le Goff, J. (1985). Lo maravilloso en el Occidente medieval. En Lo maravilloso y lo cotidiano en el Occidente medieval (pp. 9-24). Barcelona: Gedisa.

Lemarchand, M-J. (trad.) (1986). Viaje de San Brandán. Madrid: Siruela.

Ménard, Ph. (1968). Syntaxe de l'ancien français. Bordeaux: Sobodi.

Menéndez Pidal, G. (1951). Cómo trabajaron las escuelas alfonsíes. Nueva Revista de Filología Hispánica, V(4), 363-380. Recupe- 
rado de https://nrfh.colmex.mx/index. $\mathrm{php} / \mathrm{nrfh} / \mathrm{article} / \mathrm{view} / 196 / 196$

Ollier M-L. (1978). Le présent du récit. Temporalité et roman en vers. Grammaires du texte médiéval. Langue française, 40, 99-112. Recuperado de https://www.persee.fr/doc/ 1fr_0023-8368_1978_num_40_1_6139

Real Academia Española. (2018). Diccionario de la lengua española, 23. ${ }^{a}$ ed., versión 23.2 en línea. Consultado en https://dle.rae.es

Rubio Tovar, J. (1999). Consideraciones sobre la traducción de textos medievales. En E. Muñoz Raya y J. Paredes (eds.), Traducir la Edad Media: la traducción de la literatura medieval románica (pp. 43-62). Granada: Universidad de Granada.

Russell, D. W. (ed.), Zatta, J. D. (trad.) y Wogan-Browne, J. (rev.) (2005). Vieseinte Osith, virge et martire. Papers on Language \& Literature, 41(3-4), 300-445. Recuperado de http://margot.uwaterloo.ca/campsey/ DossierOsith2.pdf
Schleiermacher, F. (2012). On the different methods of translating. En L. Venuti (ed.), The translation studies reader (pp. 4363). Nueva York: Routledge.

Vanderschelden, I. (1998). Authority in literary translation: Collaborating with the author. Translation Review, 56(1), 22-31. Recuperado de https://www.tandfonline. com/doi/abs/10.1080/07374836.1998.1 0523727

Zancarini, J-C. (2002). Le métier de la traduction. EUtropia: revue italo-française, 2532. Recuperado de https://halshs.archives-ouvertes.fr/halshs-00419108

Zink, M. (1999). Littérature(s). En J. Le Goff y J-C. Schmitt (dirs.), Dictionnaire raisonné de l'Occident médiéval (pp. 610-624). París: Éditions Fayard.

Zumthor, P. (1972). Essai de poétique médiévale. París: Seuil.

Zumthor, P. (1989). La letra y la voz de la "literatura" medieval. Madrid: Cátedra.

Cómo citar este artículo: Alcatena, M. E. y Dumas, M. (2019). Traslación de textos medievales en lengua vernácula. Reflexiones a partir de una experiencia de traducción colaborativa de la Vie seinte Osith, virge e martire. Mutatis Mutandis, Revista Latinoamericana de Traducción, 12(2), 386-405. DOI: 10.17533/udea.mut.v12n2a03 